\title{
Atividade antifúngica de óleos essenciais sobre espécies de Candida
}

\author{
Igara de Oliveira Lima, Rinalda de Araújo Guerra Oliveira, Edeltrudes de Oliveira Lima*, \\ Nilma Maria Porto Farias, Evandro Leite de Souza
}

\author{
Universidade Federal da Paraíba, Departamento de Ciências Farmacêuticas, Laboratório de Micologia, \\ 58051-970, João Pessoa, PB, Brasil
}

\begin{abstract}
RESUMO: A candidíase apresenta-se como uma infecção fúngica superficial ou profunda causada por leveduras pertencentes ao gênero Candida, sendo considerada a principal infecção micótica em ambiente nosocomial. O objetivo do presente estudo foi determinar a concentração inibitória mínima - CIM do óleo essencial de Cinnamomum zeylanicum Blume, Citrus limon Risso, Eucalyptus citriodora HK, Eugenia uniflora L., Peumus boldus Benth e de Rosmarinus officinialis L. sobre cepas de Candida albicans, C. guilliermondii, C. krusei, C. parapsilosis, C. stellatoidea e C. tropicalis. Os ensaios de atividade antifúngica foram realizados através da técnica de difusão em meio sólido. Os óleos essenciais de C. zeylanicum e $P$. boldus mostraram os mais destacáveis resultados, visto que inibiram o crescimento de $58 \%$ das cepas ensaiadas e apresentaram CIM de $4 \%$.
\end{abstract}

Unitermos: Atividade antifúngica, Óleos essenciais, Cândida, leveduras, micoses.

\begin{abstract}
Antifungal activity from essential oils on Candida species" Candidiasis occurs as a superficial or profound fungal infection caused by yeasts belonging to the Candida genus. This infectious has been considered the main mycotic infection in the nosocomial environment. The aim of this study was to determine the minimum inhibitory concentration - MIC of Cinnamomum zeylanicum Blume, Citrus limon Risso, Eucalyptus citriodora HK, Eugenia uniflora L., Peumus boldus Benth and Rosmarinus officinialis L. essential oils against Candida albicans, C. guilliermondii, C. krusei, C. parapsilosis, C. stellatoidea e C. tropicalis strains. The antifungal activity assays were carried out by solid medium diffusion technique. C. zeylanicum and P. boldus essential oils showed the most prominent results which inhibited the growth of $58 \%$ of the assayed yeasts strains and presented MIC of $4 \%$.
\end{abstract}

Keywords: Antifungal activity, essential oils, Candida, yeasts, mycoses.

\section{INTRODUÇÃO}

Espécies de Candida e de Criptococcus são reconhecidas como as leveduras mais usualmente envolvidas na etiologia de infecções micóticas. A candidíase caracteriza-se como a infecção fúngica mais comum, sendo $C$. albicans seu agente etiológico mais freqüente. Ainda, outras espécies inseridas no gênero Candida (e.g. C. guilliermondii, C. krusei, C. parapsilosis, C. stellatoidea, C. tropicallis) também podem estar envolvidas na etiologia da candidíase. Os quadros clínicos mais rotineiramente reportados relacionados à candidíase são a do tipo cutâneo-mucosa, sistêmica/visceral e alérgica (Lacaz et al., 1991; Anaisse, 1992; Sidrim; Moreira, 1999).

Os pacientes imunocomprometidos possuem uma maior probabilidade de serem acometidos por infecções fúngicas, como os indivíduos portadores de leucemia, linfoma, diabetes mellitus e síndrome da imunodeficiência adquirida. Os fungos são de uma forma geral, organismos do meio externo excetuando-se algumas espécies de Candida. Desta forma, os fungos que entram em contato com o ser humano e animais podem causar alguns danos, os quais podem variar de micoses superficiais benignas (e.g. piedra nigra) até micoses mais severas (e.g. murcomicoses) (Hazen, 1995).

Uma grande quantidade de fármacos obtida através da síntese orgânica têm sido utilizada no tratamento de infecções micóticas. Os antisépticos como tintura de iodo, violeta de genciana, ácido salicílico e benzóico, derivados sulfamídicos, corantes, quinonas, antifúngicos poliênicos (e.g. nistatina, anfotericina) têm sido amplamente utilizados na terapia antimicótica (Berhan, 1957; Cury et al., 1977; Nassis et al., 1989). Ainda, faz-se uso dos chamados antifúngicos modernos, a citar os azóis (cetoconazol, econozal, sulconazol, miconazol, clotrimazol, feuconazol), alilaminas (naftina, terbinafina), hidroxipiridona, morfolina, compostos de selenium e anfotericina B lipossômica (Recio et al., 1989; Crissey et al., 1995). Com freqüência, as infecções fúngicas são de difícil tratamento, fato intrinsecamente relacionado à aquisição por parte de seus agentes etiológicos de resistência frente à ação de antifúngicos (Araújo et al., 2004).

Os óleos essenciais constituem os elementos voláteis contidos em muitos órgãos vegetais, e, estão relacionados com diversas funções necessárias à sobrevivência vegetal, exercendo papel fundamental na 
Tabela 1. Óleos essenciais derivados de plantas medicinais que apresentaram atividade antifúngica contra Candida e seus usos na medicina popular.

\begin{tabular}{|c|c|c|c|c|}
\hline Espécie & Família & $\begin{array}{l}\text { Nome } \\
\text { popular }\end{array}$ & $\begin{array}{l}\text { Parte } \\
\text { utilizada* }\end{array}$ & Usos na medicina popular (Ref.) \\
\hline $\begin{array}{l}\text { Cinnamomum } \\
\text { zeylanicum Blume }\end{array}$ & Lauraceae & Canela & Casca & $\begin{array}{l}\text { Além de aromática é tônica, } \\
\text { estimulante e antiespasmódica } \\
\text { (Corrêa, 1984) }\end{array}$ \\
\hline Citrus limon Risso & Rutaceae & Limão & Folhas & $\begin{array}{l}\text { Bronquite, dor de cabeça, } \\
\text { afrouchar catarro, garganta, } \\
\text { gripe mal curada, pulmão, } \\
\text { rinite, tosse (Vendruscolo et al., } \\
\text { 2005) }\end{array}$ \\
\hline $\begin{array}{l}\text { Eucalyptus citriodora } \\
\text { HK. }\end{array}$ & Myrtaceae & Eucalipto & Folhas & $\begin{array}{l}\text { Feridas da pele (Oliveira et al., } \\
\text { 2006) }\end{array}$ \\
\hline Eugenia uniflora L. & Myrtaceae & Pitanga & Folhas & $\begin{array}{l}\text { Cólica, colite, desarranjo, } \\
\text { disenteria, diarréia, dor de } \\
\text { barriga (Vendruscolo et al., } \\
2005 \text { ) }\end{array}$ \\
\hline Peumus boldus Benth. & Lamiaceae & $\begin{array}{l}\text { Boldo do } \\
\text { Chile }\end{array}$ & Folhas & $\begin{array}{l}\text { Dor abdominal, flatulência, } \\
\text { hepatoprotetor, colerético e } \\
\text { colagogo (Mengue et al., 2001; } \\
\text { Tôrres et al., 2005) }\end{array}$ \\
\hline $\begin{array}{l}\text { Rosmarinus officinalis } \\
\text { L. }\end{array}$ & Lamiaceae & Alecrim & Folhas & $\begin{array}{l}\text { Verme e tosse quando associada } \\
\text { a outras plantas (Tôrres et al., } \\
2005 \text { ) }\end{array}$ \\
\hline
\end{tabular}

* parte da planta utilizada na extração do óleo essencial.

defesa contra microrganismos (Siqui et al., 2000). Ainda, tem sido estabelecido cientificamente que cerca de $60 \%$ dos óleos essenciais possuem propriedades antifúngicas e $35 \%$ exibem propriedades antibacterianas (Bhavanani; Ballow, 1992).

Oliveira et al. (2006) verificaram que o óleo essencial de E. citriodora apresenta sinergismo com ampicilina,cloranfenicoletetraciclinafrenteS. epidermidis. Com relação a $S$. aureus, houve diminuição da atividade inibitória de ampicilina, cloranfenicol e gentamicina. Tetraciclina, quando aplicado em combinação com o óleo essencial de E. citriodora evidenciou sinergismo nas interações com todas as bactérias testadas. E. citriodora tem se caracterizado como uma das espécies mais utilizadas no nordeste brasileiro como planta medicinal (Estanislau et al., 2001).

Pessini et al. (2003) avaliaram 13 plantas usadas freqüentemente na medicina popular para o tratamento de doenças infecciosas. Entre as plantas Eugenia uniflora inibiu o desenvolvimento de algumas cepas de bactérias e fungos. Os resultados obtidos vêm corroborar com a crença popular que utiliza essas plantas no tratamento de várias doenças infecciosas.

Bara e Vanetti (1997/1998) avaliaram o potencial antibacteriano de dezesseis espécies de plantas tidas como medicinais. Os extratos hidroalcoólicos das espécies Cinnamomum zeylanicum e Rosmarinus officinalis estavam entre os menos ativos.

Nesta perspectiva, muitos estudos têm sido realizados com ênfase na busca de novos produtos naturais ou sintéticos possuidores de atividade antimicrobiana atrelada a uma menor toxicidade ao hospedeiro (Anaisse, 1992; Edwards Jr; Filler, 1992; Graybill, 1992). O objetivo deste trabalho foi avaliar a eficácia de óleos essenciais de plantas medicinais na inibição do crescimento de espécies de leveduras pertencentes ao gênero Candida.

\section{MATERIAL E MÉTODOS}

\section{Óleos essenciais}

Os óleos essenciais que tiveram sua atividade antifúngica avaliada foram obtidos de seis espécies vegetais regionais de reconhecidas propriedades medicinais (Tabela 1). As referidas espécies foram identificadas pelo botânico Dr. José Roberto Lima, sendo catalogadas e registradas no Herbário Lauro Xavier Filho, Departamento de Sistemática e Ecologia, Centro de Ciências Exatas e da Natureza, UFPB. Os óleos essenciais foram extraídos no Laboratório de Tecnologia Farmacêutica, Departamento de Ciências Farmacêuticas, Centro de Ciências da Saúde, UFPB através da técnica de hidrodestilação (Matos et al., 1981).

\section{Preparação das soluções dos óleos essenciais}

Em tubo estéril foi adicionado $0,4 \mathrm{~mL}$ do óleo essencial, $0,04 \mathrm{~mL}$ de Tween 80 e q.s.p. $5 \mathrm{~mL}$ de água 
Tabela 2. CIM dos óleos essenciais de plantas medicinais sobre cepas pertencentes ao gênero Candida (resultados expressos em diâmetro em mm dos halos de inibição do crescimento fúngico).

\begin{tabular}{|c|c|c|c|c|c|c|c|c|c|}
\hline \multirow{3}{*}{ Cepas fúngicas } & \multicolumn{6}{|c|}{ Óleos essenciais } & \multirow{3}{*}{$\begin{array}{l}\infty \\
\infty \\
\overline{0} \\
0 \\
3\end{array}$} & \multirow{3}{*}{ 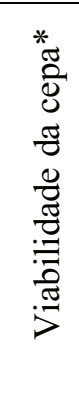 } & \multirow{3}{*}{ 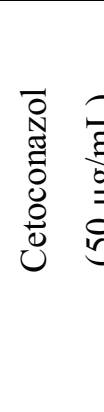 } \\
\hline & 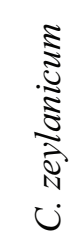 & ن & 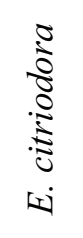 & 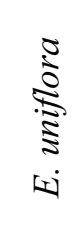 & $\begin{array}{l}\frac{5}{8} \\
\frac{8}{8} \\
0\end{array}$ & 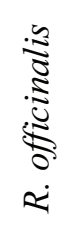 & & & \\
\hline & $4 \%$ & $4 \%$ & $8 \%$ & $2 \%$ & $4 \%$ & $8 \%$ & & & \\
\hline $\begin{array}{l}\text { C. albicans } \\
\text { FCF-243 }\end{array}$ & 13 & 0 & 0 & 0 & 10 & 0 & 0 & + & 25 \\
\hline $\begin{array}{c}\text { C. albicans } \\
\text { ATCC-76615 }\end{array}$ & 12 & 12 & 0 & 0 & 13 & 10 & 0 & + & 28 \\
\hline $\begin{array}{l}\text { C. guilliermondii } \\
\text { MD-92 }\end{array}$ & 0 & 0 & 10 & 0 & 0 & 0 & 0 & + & 27 \\
\hline $\begin{array}{c}\text { C. guilliermondii } \\
\text { LM-6T }\end{array}$ & 14 & 13 & 24 & 0 & 20 & 13 & 0 & + & 27 \\
\hline $\begin{array}{l}\text { C. krusei } \\
\text { FCF } 161\end{array}$ & 12 & 0 & 0 & 0 & 10 & 0 & 0 & + & 25 \\
\hline $\begin{array}{l}\text { C. krusei } \\
\text { FCF-281 }\end{array}$ & 0 & 10 & 13 & 12 & 23 & 12 & 0 & + & 30 \\
\hline $\begin{array}{l}\text { C. parapsilosis } \\
\text { ME-2 }\end{array}$ & 17 & 0 & 0 & 0 & 0 & 0 & 0 & + & 25 \\
\hline $\begin{array}{l}\text { C. parapsilosis } \\
\text { MD-6 }\end{array}$ & 13 & 12 & 16 & 0 & 0 & 12 & 0 & + & 25 \\
\hline $\begin{array}{l}\text { C. stellatoidea } \\
\text { LM-41V }\end{array}$ & 10 & 12 & 12 & 0 & 21 & 7 & 0 & + & 25 \\
\hline $\begin{array}{l}\text { C. stellatoidea } \\
\text { LM-46V }\end{array}$ & 0 & 0 & 0 & 0 & 0 & 0 & 0 & + & 25 \\
\hline $\begin{array}{l}\text { C. tropicalis } \\
\text { MD-40 }\end{array}$ & 0 & 0 & 0 & 0 & 0 & 0 & 0 & + & 26 \\
\hline $\begin{array}{l}\text { C. tropicalis } \\
\text { MD-127 }\end{array}$ & 0 & 0 & 0 & 0 & 10 & 0 & 0 & + & 25 \\
\hline
\end{tabular}

* crescimento da levedura em ASD sem adição de óleo essencial ou antifúngico padrão.

destilada estéril, sendo agitado por 5 minutos usando-se aparelho Vortex (Fanem), obtendo-se uma solução com concentração final de $8 \%$ do óleo essencial. A partir de tal solução, utilizando o procedimento de diluição seriada, obtiveram-se as demais soluções nas seguintes concentrações: $4,2,1,0,0.5$ e $0.25 \%$ (Allegrini et al., 1973).

\section{Espécies fúngicas}

C. albicans FCF-243, C. albicans ATCC-76615, C. guilliermondii MD-92, C. guilliermondii LM-6T, $C$. krusei FCF-161, C. krusei FCF-281, C. parapsilosis ME2, C. parapsilosis MD-6, C. stellatoidea LM-41V, C. stellatoidea LM46V, C. tropicalis MD-40, C. tropicalis MD-127 foram utilizadas como microrganismos testes. As cepas foram mantidas em ágar Sabouraud dextrose -
ASD a uma temperatura de $4{ }^{\circ} \mathrm{C}$, sendo utilizados para os ensaios repiques de 24 horas em ASD incubados a 35 ${ }^{\circ} \mathrm{C}$. No estudo da atividade antimicrobiana utilizou-se um inóculo fúngico de aproximadamente $10^{6} \mathrm{UFC} / \mathrm{mL}$ padronizado de acordo com a turbidez do tubo 0,5 da escala de McFarland.

\section{Ensaios de atividade antifúngica}

Os ensaios de avaliação da atividade antifúngica dos óleos essenciais foram realizados pelo método de difusão em meio sólido utilizando cavidades em placa (Cleeland; Squires, 1991; Hadaceck; Greger, 2000). Em placas de Petri estéreis foi adicionado $1 \mathrm{~mL}$ da suspensão fúngica, em seguida verteu-se $20 \mathrm{~mL}$ de ASD fundido e resfriado a $45-50{ }^{\circ} \mathrm{C}$. Após solidificação do ágar, foram feitas cavidades com cânulas de vidro estéreis $(6 \mathrm{~mm}$ de 
diâmetro) onde depositou-se $50 \mu \mathrm{L}$ da solução ajustada na concentração desejada do óleo essencial testado. $\mathrm{O}$ sistema foi incubado por $24-48$ a $35^{\circ} \mathrm{C}$. Após término do período de incubação, foi considerado como CIM àquela concentração do oléo essencial capaz de desenvolver um halo de inibição do crescimento fúngico maior ou igual a 10 mm de diâmetro.

Paralelamente, foram realizados controle da viabilidade das cepas de leveduras ensaiadas. Ainda, realizou-se controle de sensibilidade das cepas ensaiadas frente à ação do Tween 80 e do antifúngico padrão cetoconazol $(50 \mu \mathrm{g} / \mathrm{mL})$, sendo ambos os ensaios realizados através da técnica de difusão em meio sólido utilizando discos de papel de filtro (Bauer et al., 1966).

\section{RESULTADOS E DISCUSSÃO}

A Tabela 2 mostra os resultados dos ensaios para a determinação da CIM dos óleos essenciais de $C$. zeylanicum, C. limon, E. citriodora, Eugenia uniflora, $P$. boldus e $R$. officinalis. Observa-se que todos os óleos essenciais apresentaram efetividade de inibição de pelo menos uma cepa fúngica ensaiada, caracterizado pela formação de halos de inibição do crescimento microbiano com diâmetro igual ou superior a $10 \mathrm{~mm}$. Entre os resultados obtidos, ressalta-se a atividade anti-Candida mostrada pelos óleos essenciais de C. zeylanicum e $P$. boldus, visto ambos inibirem o crescimento da maioria das cepas ensaiadas (58\%). Esta destacável propriedade de inibição pode ser verificada quando observado os diâmetros dos halos de inibição do crescimento das leveduras (10-23 mm) frente à ação da CIM de tais óleos essenciais.

A sensibilidade das cepas de leveduras frente aos óleos essenciais de C. zeylanicum e P. boldus apresentouse diferenciada, pois ocorreu o desenvolvimento de halos de inibição do crescimento com diferentes diâmetros quando da ação dos dois óleos essenciais na concentração de 4\% (e.g C. albicans ATCC-76615, C. guilliermondii LM-6T). Esta diferenciada propriedade antifúngica entre estes dois óleos essenciais também pode ser verificada pelo fato de uma cepa mostrar-se sensível a um óleo essencial e resistente ao outro (e.g. C. krusei FCF-161, C. tropicalis MD-127). Cabe ressaltar que as cepas de $C$. guilliermondii MD-92 e C. stellatoidea MD-40 apresentaram comportamento de resistência aos óleos essenciais de $C$. zeylanicum e P. boldus.

Os resultados obtidos neste estudo considerando os óleos essenciais de $C$. zeylanicum e $P$. boldus encontram-se compatíveis com os achados de outros autores (Farias; Lima, 2000; Belém, 2002; Araújo et al., 2004). Tais pesquisas encontraram que estes óleos essenciais apresentaram CIM entre 2 e $8 \%$ quando em interação com cepas de bactérias (Staphylococus, Listeria e Pseudomonas) e fungos (Candida e Malassezia).

Os óleos essenciais de $C$. limon, E. citriodora $\mathrm{e}$ $R$. officinalis mostraram uma baixa efetividade antifúngica quando comparado aos resultados obtidos com os óleos essenciais de $C$. zeylanicum e $P$. boldus. O óleo essencial de E. uniflora apresentou um baixo poder de inibição sobre as cepas de Candida, porém detectou-se atividade inibitória sobre C. krusei FCF-281. De uma forma geral, C. tropicalis mostrou-se como a espécie mais resistente à ação dos óleos essenciais testados.

O óleo essencial de C. limon a $4 \%$ inibiu 05 (42\%) das cepas ensaiadas, sendo desenvolvidos halos de inibição de crescimento com diâmetro igual ou próximo a $10 \mathrm{~mm}$. Resultados similares foram registrados por Belém (2002) em avaliação da efetividade de tal produto na inibição do crescimento de M. furfur. O óleo essencial de $R$. officinalis mostrou-se ativo somente sobre 04 cepas ensaidas, sendo observado halos de inibição com diâmetro de no máximo $12 \mathrm{~mm}$ (C. krusei FCF-281, C. parapsilosis MD-6). Esta incipiente propriedade antileveduriforme do óleo essencial de $R$. officinalis também foi observada por Araújo (2003) sobre cepas de Candida isoladas de meio ambiente. O óleo essencial de E. citriodora a $8 \%$ mostrou-se ativo na inibição de quatro cepas ensaiadas com formação de halos de inibição com diâmetro de até 24 mm (C. guilliermondii LM-6T). Pontes (2002) observou que o óleo essencial de E. citriodra em concentração de $8 \%$ apresentou satisfatório poder antifúngico quando em interação com cepas de Trichosporon inkin.

A maior ou menor atividade biológica dos óleos essenciais tem se mostrado dependente da composição de seus constituintes químicos como citral, pineno, cineol, cariofileno, elemeno, furanodieno, imoneno, eugenol, eucaliptol, carvacrol e outros. Estes constituintes são responsáveis pelas propriedades antissépticas, antibacteiranas, antifúngicas e antiparasíticas (Craveiro et al., 1981; Souza et al., 2005).

Considerando a resistência das leveduras pertencentes ao gênero Candida frente aos antifúngicos atualmente utilizados, pode-se inferir que a pesquisa de busca de novos compostos antifúngicos de origem vegetal mostra-se de relevante significância. É possível observar o potencial antibiótico que os produtos vegetais possuem, e por conseqüência, a real possibilidade de aplicação destes produtos na prevenção e tratamento de doenças infecciosas de origem fúngica. Porém, é necessário citar a necessidade de realização de estudos de cunho toxicológico e clínico como suporte de segurança para o uso destes produtos como fármacos.

\section{REFERÊNCIAS}

Allegrini M, Siméon M, Maillos H, Boiloot A 1973. Èmulsions et applications en microbiologie. Trav Soc Pharm Montp 33: 73-86.

Anaisse E 1992. Oportunistic mycoses in the immunocompromised host: experience at a Cancer Center and review. Clin Infect Dis 14: 43-53.

Araújo JCLV 2003. Perfil de sensibilidde de microrganismos oportunistas de origem clínica e ambiental a óleos essenciais. João Pessoa, 77p. Dissertação de Mestrado

Rev. Bras. Farmacogn. Braz J. Pharmacogn. 16(2):abr/jun. 2006 
em Produtos Naturais e Sintéticos Bioativos, Universidade Federal da Paraíba.

Araújo JCLV, Lima EO, Ceballos BSO, Freire KRL, Souza EL, Santos Filho L 2004. Ação antimicrobiana de óleos essenciais sobre microrganismos potencialmente causadores de infecções oportunistas. Rev Patol Trop 33: 55-64.

Bara MTF, Vanetti MCD 1997-1998. Estudo da atividade antibacteriana de plantas medicinais, aromáticas e corantes naturais. Rev Bras Farmacogn 7-8: 21-34.

Bhavanani SM, Ballow CH 1992. New agents for Gram-positive bacteria. Curr Opin Microbiol 13: 528-534.

Bauer AW, Kirby WM, Sherris SC, Turck M 1966. Antibiotic susceptibility testing by a standardized single disc method. Am J Clin Pathol 45: 493-496.

Belém LF 2002. Estudo epidemiológico da pitiríase versicolor no estado da Paraíba e avaliação química e antifúngica de produtos naturais e sintéticos contra seu agente etiológico. João Pessoa, 178p.Tese de Doutorado em Produtos Naturais e Sintéticos Bioativos, Universidade Federal da Paraíba.

Berhan R.W 1957. Species of Candida most frequently isolated from man: methods and criteria for their identification. J Chron Dis 5: 460-472.

Cleeland L, Squires E 1991. Evaluation of new antimicrobials in vitro and experimental animal infections. In V.M.D. Lorian. Antibiotics in Laboratory Medicine. Baltimore: Williams e Wilkins, p. 739-788.

Corrêa MP 1984. Dicionário das Plantas Úteis do Brasil e das Exóticas Cultivadas. Ministério da Agricultura, IBDF, Vol. 1. p. 458.

Craveiro AA, Fernandes AG, Andrade CHS, Matos FJA, Alencar JW, Machado MIL 1981. Óleos essenciais de Plantas do Nordeste. Fortaleza: Editora UFC.

Crissey JT, Lang H, Parish LC 1995. Manual of Medical Mycology. Cambridge: Blackwell Science.

Cury AE, Minami PS, Parra DS 1977. Sensibilidade in vitro de leveduras do gênero Candida à violeta de genciana. Rev Microbiol 8: 84-88.

Edwards Jr JE, Filler SG 1992. Current strategy for treating invasive candidiasis: emphasis on infections in nonneutropenic patients. Clin Infect Dis 14: 106-113.

Estanislau AA, Barros FAZ, Peña AP, Santos SC, Ferri PH, Paula JR 2001. Composição química e atividade antibacteriana dos óleos essenciais de cinco espécies de Eucalyptus cultivadas em Goiás. Rev Bras Farmacogn 11: 95-98.

Farias NMP, Lima EO 2000. Atividade antifúngica de óleos essenciais obtidos de plantas medicinais contra leveduras do gênero Candida: uma alternativa no controle da infecção hospitalar. XVI Prêmio Jovem Cientista. Edição: Saúde da população, Controle da Infecção Hospitalar. Porto Alegre, Brasil.

Graybill JR 1992. Future directions of antifungal chemotherapy. Clin Infect Dis 14: 170-181.

Hadaceck F, Greger H 2000. Testing of antifungical natural products: methodologies, comparability of results and assay choice. Phytoch Anal 11: 137-147.

Hazen KC 1995. New and emerging pathogen yeasts. Clin Microbiol Rev 8: 462-478.

Lacaz CS, Porto E, Martins JEC 1991. Micologia Médica. São Paulo: Sarvier.

Matos FJ, Craveiro AA, Fernandes CHS 1981. Óleos Essenciais de Plantas Medicinais do Nordeste. Fortaleza: Edições UFC.

Mengue SS, Mentz LA, Schenkel EP 2001. Uso de plantas medicinais na gravidez. Rev Bras Farmacogn 11: 2135.

Nassis CZ, Griesbrecht AM, Saito ML, Oliveira F 1989. Atividade antibiótica de extratos de espécies de Annonaceae. Cienc Cult 41: 527-532.

Oliveira RAG, Lima EO, Vieira WL, Freire KRL, Trajano VN, Lima IO, Souza EL, Toledo MS, Silva-Filho RN 2006. Estudo da interferência de óleos essenciais sobre a atividade de alguns antibióticos usados na clínica. Rev Bras Farmacogn 16: 77-82.

Pessini GL, Holetz FB, Sanches NR, Cortez DAG, Dias-Filho BP, Nakamura CV 2003. Avaliação da atividade antibacteriana e antifúngica de extratos de plantas utilizados na medicina popular. Rev Bras Farmacogn 13(Supl. 1): 21-24.

Pontes ZBVS 2002. Atividade antifúngica de produtos naturais e sintéticos sobre espécies de Trichosporon behrend. João Pessoa, 178p. Tese de Doutorado em Produtos Naturais e Sintéticos Bioativos, Universidade Federal da Paraíba.

Recio MC, Rios JL, Villar A 1989. A review of some antimicrobial compounds isolated from medicinal plants reported in the literature 1978-1988. Phytother Res 3: 117-125.

Sidrim JC, Moreira JLB 1999. Fundamentos Clínicos e Laboratoriais da Micologia Médica. Guanabara Koogan: Rio de Janeiro.

Siqui AC, Sampaio, ALF, Sousa MC, Henriques MGMO, Ramos, MFS 2000. Óleos essenciais - potencial antiinflamatório. Biotecnologia, Ciência e Desenvolvimento 16: 38-43.

Souza EL, Lima EO, Freire KRL, Sousa CP 2005. Inhibitory action of some essential oils and phytochemicals on the growth of moulds isolated from foods. Braz Arch Biol Technol 48: 245-250.

Tôrres AR, Oliveira RAG, Diniz MFFM, Araújo EC 2005. Estudo sobre o uso de plantas medicinais em crianças hospitalizadas da cidade de João Pessoa: riscos e benefícios. Rev Bras Farmacogn 15: 373-380.

Vendruscolo GS, Rates SMK, Mentz LA 2005. Dados químicos e farmacológicos sobre as plantas utilizadas como medicinais pela comunidade do bairro Ponta Grossa, Porto Alegre, Rio Grande do Sul. Rev Bras Farmacogn 15: 361-372. 